\title{
Peanut Yield Loss in the Presence of Defoliation Caused by Late or Early Leaf Spot
}

\author{
Daniel J. Anco, ${ }^{1, \dagger}$ James S. Thomas, ${ }^{1}$ David L. Jordan, ${ }^{2}$ Barbara B. Shew, ${ }^{3}$ W. Scott Monfort, ${ }^{4}$ Hillary L. Mehl, ${ }^{5}$ Ian M. Small, ${ }^{6}$ \\ David L. Wright, ${ }^{6}$ Barry L. Tillman, ${ }^{7}$ Nicholas S. Dufault, ${ }^{8}$ Austin K. Hagan, ${ }^{9}$ and H. Lee Campbell ${ }^{9}$ \\ ${ }^{1}$ Department of Plant and Environmental Sciences, Clemson University, Edisto Research and Education Center, Blackville, \\ SC 29817 \\ ${ }^{2}$ Department of Crop and Soil Sciences, North Carolina State University, Raleigh, NC 27695 \\ ${ }^{3}$ Department of Entomology and Plant Pathology, North Carolina State University, Raleigh, NC 27695 \\ ${ }^{4}$ Department of Crop \& Soil Sciences, University of Georgia, Tifton, GA 31793 \\ ${ }^{5}$ Tidewater Agricultural Research and Extension Center, Virginia Tech, Suffolk, VA 23437 \\ ${ }^{6}$ North Florida Research and Education Center, University of Florida, Quincy, FL 32351 \\ ${ }^{7}$ North Florida Research and Education Center, University of Florida, Marianna, FL 32446 \\ ${ }^{8}$ Department of Plant Pathology, University of Florida, Gainesville, FL 32611 \\ ${ }^{9}$ Department of Entomology and Plant Pathology, Auburn University, Auburn, AL 36849
}

\begin{abstract}
Late and early leaf spot, respectively caused by Nothopassalora personata and Passalora arachidicola, are damaging diseases of peanut (Arachis hypogaea) capable of defoliating canopies and reducing yield. Although one of these diseases may be more predominant in a given area, both are important on a global scale. To assist informed management decisions and quantify relationships between end-of-season defoliation and yield loss, meta-analyses were conducted over 140 datasets meeting established criteria. Slopes of proportion yield loss with increasing defoliation were estimated separately for Virginia and runner market type cul-

Results for runner market type cultivars showed yield loss to linearly increase 2.2 to $2.8 \%$ per $10 \%$ increase in defoliation for levels up to approximately $95 \%$ defoliation, after which the rate of yield loss was exponential. Defoliation thresholds to prevent economic yield loss for Virginia and runner types were estimated at 40 and $50 \%$, respectively. Although numerous factors remain important in mitigating overall yield losses, the integration of these findings should aid recommendations about digging under varying defoliation intensities and peanut maturities to assist in minimizing yield losses.
\end{abstract} tivars. Yield loss for Virginia types was described by an exponential function over the range of defoliation levels, with a loss increase of 1.2 to $2.2 \%$ relative to current loss levels per additional percent defoliation.
Keywords: Arachis hypogaea, digging, groundnut, harvest, inversion, quantitative synthesis, senescence
Over the past 100 years, peanut (Arachis hypogaea L.) has been grown on $>400,000$ hectares per year in the United States, with annual amounts from 2013 to 2017 averaging 615,000 hectares and corresponding to a production value of $>\$ 1.22$ billion per year (USDA-NASS 2019). Approximately $94 \%$ of this production by weight is represented by two market types: runner and Virginia (USDA NASS 2019). Late leaf spot caused by Nothopassalora personata (Berk. \& M.A. Curtis) S.A. Khan \& M. Kamal (syn. Cercosporidium personatum [Berk. \& M.A. Curtis] Deighton) and early leaf spot caused by Passalora arachidicola (syn. Cercospora arachidicola [Hori]) are responsible for the greatest losses among peanut biotic diseases (Whitty et al. 2000; York et al. 1994). Yield loss potentials for these two diseases were previously reported to be similar on peanut (Backman and Crawford 1984). In the absence of fungicide sprays, leaf spots can cause yield losses $>50 \%$ (Kokalis-Burelle et al. 1997), corresponding to $>\$ 990$ per hectare (Anco et al. 2019) or $\$ 600$ million annually (Whitty et al. 2000), not including additional fungicide management costs, which can readily exceed $\$ 250 /$ ha.

\section{${ }^{\dagger}$ Corresponding author: D. J. Anco; danco@clemson.edu}

Funding: We thankfully appreciate the South Carolina Peanut Board and the National Peanut Board for supporting this work. This material is based on work supported by the NIFA/USDA under project number SC-1700532.

*The $\boldsymbol{e}$-Xtra logo stands for "electronic extra" and indicates that two supplementary tables are published online.

The author(s) declare no conflict of interest.

Accepted for publication 19 December 2019

(C) 2020 The American Phytopathological Society
Profitability of a given peanut crop grown under contract is based on farmer stock weight and grade (USDA FSA 2018). Peanuts at optimal maturity weigh more than immature peanuts (Carter et al. 2017; Pattee et al. 1977) and are consequently more valuable. Digging decisions directly influence the profitability of a peanut field (Anco et al. 2019; Jordan et al. 2018a), and multiple abiotic (e.g., weather and soil) and biotic (e.g., crop health and maturity) factors can affect the decision of when to dig a particular field. In addition to adverse weather limiting field access, severe defoliation caused by leaf spot diseases can prematurely deteriorate pegs and increase pod loss (Bourgeois et al. 1991; Jordan et al. 2016; Nutter and Shokes 1995) before peak maturity development. Questions about optimal digging times in the presence of defoliation caused by leaf spot diseases are common each year. Guidelines have previously suggested that yield loss increases rapidly when defoliation exceeds $30 \%$ (Carley et al. 2009; Kokalis-Burelle et al. 1997), whereas other research reported the relationship between yield loss and defoliation levels to be more variable (Carley et al. 2009; Jordan et al. 2016). As with defoliation levels, peanut yield loss has previously been related to canopy reflectance (Aquino et al. 1992; Nutter and Littrell 1996). Although individual methods of disease evaluation can confer distinct benefits and may better quantify particular phases of an epidemic (e.g., incidence at initial phases compared with plant death at terminal phases), amount of defoliation as a measurement represents a relative compromise between foliar leaf spot disease accumulation, interpretability, and assessment approachability.

The objective of this research was to examine the relationship between peanut yield loss and defoliation for Virginia and runner market types as produced in the southeast and Virginia-Carolina regions of the United States via meta-analytic techniques (Madden and Paul 2011; Simmonds et al. 2005). This approach allows quantification of trends across a group of data from multiple years and locations. This work sought to address two main questions: (i) After how much defoliation does statistically significant yield loss occur, with losses 
additionally examined economically, and (ii) how much defoliation can an immature crop sustain before yield loss outpaces potential yield gain? Whereas the first question aims to quantify the loss in relation to increasing defoliation when a crop is mature, the second question aims to apply this relationship to a crop that is still developing so that this information can be considered alongside other abiotic or biotic factors that might be present around the time when digging decisions are made.

\section{Materials and Methods}

Study data. To examine the relationship of peanut yield loss in the presence of defoliation caused by late and early leaf spot, three metaanalyses were conducted. Examined relationships included yield loss with increasing defoliation, relative yield increase over time, and defoliation increase over time under conducive conditions. For the first meta-analysis (M1), data from >140 studies conducted in Alabama, Florida, North Carolina, South Carolina, Texas, and Virginia from 1999 to 2017 were examined for meeting selection criteria for inclusion in the analyses. To be selected for inclusion, studies had to have reported defoliation, yield data, cultivar, and treatment; contain a final defoliation rating $\leq 21$ days before peanut inversion; have a maximum defoliation $\geq 20 \%$; contain a range of defoliation values $\geq 19 \%$; and be free of confounding factors or include sufficient data to model their effects. After screening, 108 studies (Supplementary Table S1) were identified meeting these criteria: 64 Virginia market type and 44 runner market type datasets. Virginia market type experiments were conducted in North Carolina $(n=12)$, South Carolina $(n=39)$, and Virginia $(n=13)$. Runner market type experiments were conducted in Alabama $(n=14)$, Florida $(n=22)$, South Carolina $(n=$ $2)$, and Texas $(n=6)$. Leaf spot ratings reported on the Florida 1 to 10 Scale were converted to estimated proportion defoliation via the previously reported equation (Campbell et al. 2018c; Cantonwine et al. 2007; Chiteka et al. 1988),

defoliation $=1 /(1+\exp (-[$ Florida $1-10$ Scale value -6.0672$] /$ $0.79750))$

More complex models incorporating moderator variables for cultivar, disease (late leaf spot, early leaf spot, or both), or original scale used to rate leaf spot (Florida 1 to 10 Scale or percentage defoliation) were examined but did not produce superior model fits.

For the second meta-analysis (M2), 24 datasets were examined under the following selection criteria: Cultivar and yield data needed to be reported per treatment, at least three cultivar inversion dates toward a relative optimum yield per cultivar for each experiment were present, inversion dates (days after planting) were within 21 days of optimal relative yield, and no confounding factors were present. Of these 24 datasets, 20 met the criteria. These experiments were conducted in Georgia $(n=2)$, North Carolina $(n=7)$, South Carolina $(n=10)$, and Virginia $(n=1)$; inclusion of data from a study was contingent on cultivar-level data meeting criteria. For the third meta-analysis (M3), 17 datasets were examined and 16 met the following selection criteria: Defoliation data were reported per treatment per replicate and cultivar for at least three ratings, date per defoliation rating was reported, and adequate data were available to examine rapid defoliation increase (i.e., analogous to a nontreated check in a conducive environment). Of these experiments, seven were conducted in Florida and four were conducted in South Carolina.

Yield loss with defoliation. Initial linear regressions of the M1 study dataset were conducted to estimate yield potential in the absence of defoliation and yield loss as a function of defoliation as described by Shah and Dillard (2006). Because market type can influence digging losses (Sorensen et al. 2017; Thomas et al. 1983; Troeger et al. 1976), M1 analyses were executed separately for Virginia and runner market type cultivars. State was included as a moderator variable. Data were analyzed according to the following meta-regression equations via one-stage individual patient data methods (Simmonds et al. 2005; Thompson and Higgins 2002; van Houwelingen et al. 2002):

$$
\begin{gathered}
Y_{v}=b_{0} \exp \left(b_{1} \cdot d\right)+b_{2} S+b_{3} C+\beta X+u+\varepsilon \\
Y_{r<95}=b_{1} \cdot d+b_{3} S+b_{4} T+\beta X+u+\varepsilon \\
Y_{r \geq 95}=b_{0} \exp \left(b_{2} \cdot d\right)+b_{3} S+b_{4} T+\beta X+u+\varepsilon
\end{gathered}
$$

where $Y_{v}, Y_{r<95}$, and $Y_{r \geq 95}$ are proportion yield loss for Virginia market type peanuts, runner market type peanuts with $<95 \%$ defoliation, and runner market type peanuts with $\geq 95 \%$ defoliation, respectively; $d$ is proportion defoliation; $S$ is proportion southern stem rot incidence (caused by Sclerotium rolfsii Sacc.); $C$ is proportion Cylindrocladium black rot incidence (caused by Cylindrocladium parasiticum Crous, Wingfield \& Alfenas); $X$ is a series of dummy variables for each state with corresponding vector of effects $\beta ; u$ is the random effect of study with mean 0 and variance $s_{u}^{2}$; $\varepsilon$ is the residual error (with mean 0 and variance $s_{\varepsilon}^{2}$ ); and $b_{0}$ to 4 are estimated parameters. Fixed effects of $S, C$, and $T$ (total soilborne disease incidence representing multiple nontarget diseases not otherwise differentiated, including combined southern stem rot and Rhizoctonia limb rot symptoms as per Jaks and Grichar 2009 a, b) were included to limit these factors from otherwise confounding analyses. Subscripts are suppressed for convenience. Parameters in Equations 2 and 3 were estimated concurrently. To facilitate convergence and stable estimation, $b_{0}$ and $b_{2}$ parameters from Equation 3 were reparameterized according to their expected-value parameterizations (Anco et al. 2013, 2014; Ratkowsky 1990; Schabenberger and Pierce 2002), corresponding to

$$
b_{0}=S_{1} / \exp \left(b_{2} \times 0.99284\right)
$$

and

$$
b_{2}=\log \left(S_{2} / S_{1}\right) /-0.02431
$$

with $S_{1}$ and $S_{2}$ as the respective expected-value parameters. Data were modeled with the NLMIXED procedure of SAS version 9.4 with Newton-Raphson optimization (Stroup 2013). Reliability of Equations 1 through 3 in predicting observed yield loss values was measured with the concordance correlation coefficient (CCC) (Lin 1989; Madden et al. 2007). Selection of Equations 1 through 3, rather than competing models not listed here for focus, was based on both exploratory data analysis and reduced Akaike information criterion (AIC) (Littell et al. 2006).

Confidence intervals (CIs) for parameter estimates were calculated as:

$$
\mathrm{CI}=\text { estimate } \pm t_{1-0.05 / 2, d f} \times \mathrm{SE}
$$

with corresponding $95 \%$ prediction intervals (PIs) calculated as:

$$
\mathrm{PI}=\text { estimate } \pm t_{1-0.05 / 2, d f} \times \sqrt{\left(\mathrm{SE}^{2}+\sigma^{2}\right)}
$$

where $\sigma^{2}$ is the estimated between-study variance. Confidence and prediction intervals for estimated proportion yield loss at a given defoliation level were calculated as:

$$
\mathrm{CI}=\text { estimate } \pm t_{1-0.05 / 2, d f} \times \mathrm{SE}
$$

and

$$
\mathrm{PI}=\text { estimate } \pm t_{1-0.05 / 2, d f} \times(\mathrm{SE}+\sigma)
$$

Yield loss in kilograms per hectare and dollars per hectare were calculated assuming 4,480 kg/ha and $\$ 500 / 1,000 \mathrm{~kg}$ (Virginia market type) or $\$ 470 / 1,000 \mathrm{~kg}$ (runner market type).

Relative yield and defoliation increase over time. In the initial stage of $\mathrm{M} 2$, slopes $(y=\mathrm{d} K / \mathrm{dt})$ representing proportion rate of relative yield $(K)$ increase toward a relative optimum per experiment per day, with $K$ at the first digging date (DD1) $=1$ according to the formula:

$$
\mathrm{K}=\mathrm{K}_{\mathrm{Y}} / \mathrm{K}_{\mathrm{DD} 1}
$$

where $K_{Y}$ and $K_{D D 1}$ are respectively yield at the current digging date and at DD1, were estimated per dataset according to the form: 


$$
K=y(\text { digging date })+\text { intercept }+\varepsilon
$$

Linear increases in yield have been previously reported (Boote 1982; Jordan et al. 2016). Slopes were calculated separately per study per market type in NLMIXED. Data under the second stage of M2 were modeled with Equation 6,

$$
y=\zeta+u+\varepsilon
$$

where $y$ is the slope, $\zeta$ is an intercept representing the expected effect size across studies, $u$ is the random effect of study, and $\varepsilon$ is the residual (held at 1). Data were modeled with the GLIMMIX procedure of SAS, with restricted maximum likelihood and Kenward-Roger degrees of freedom adjustment. Study weights consisted of the inverse of study sampling variance, with within-study sampling variance equal to $\mathrm{SE}_{y}^{2}$, the squared estimated standard error for estimated slope $y$ per study market type. Peanut market type was subsequently examined as a potential moderator variable but did not improve model fit by way of significant $F$ test $(P=0.843)$ and was accordingly excluded from the model. Covariance structures, as described in Madden et al. (2016), beyond the default variance component structure for the random study effect did not result in AIC values <-158.2 (AIC associated with variance component specification).

For M3, the first stage consisted of fitting the logistic model, selected after exploratory data analysis and comparison of AIC values among competing models (e.g., the Gompertz model; Madden et al. 2007), to defoliation progress data per experiment with equations of the form

$$
D=1 /\left(1+\beta_{L}\right) \exp \left(-\gamma_{L}(t-C)\right)
$$

where $D$ is proportion defoliation, $t$ is days after planting per assessment, $C$ is a relative constant (e.g., 70 to 130) used to bring the initial defoliation rating close to 0 to facilitate modeling defoliation increase from an approximate initial time zero, and $\beta_{L}$ and $\gamma_{L}$ are parameters. Model fitting was conducted in NLMIXED assuming a Gaussian distribution. The second stage of M3 was conducted with the general (univariate) form of Equation 6 and corresponding methods, substituting $\beta_{L}$ or $\gamma_{L}$ for $y$ and $\operatorname{SE}\left(\beta_{L}\right)^{2}$ or $\operatorname{SE}\left(\gamma_{L}\right)^{2}$ for $\mathrm{SE}_{y}{ }^{2}$. Similar to the M2 s-stage analysis, alternative covariance structures for the random study effect did not improve model AIC values for $\beta_{L}$ or $\gamma_{L}$ relative to the variance component-associated values of 149.6 and -48.3 , respectively.

Yield loss with defoliation in an immature crop. The relationship of defoliation and obtainable yield after digging and harvesting at varying times before maturity was explored by integrating the results of M1 to M3 under selected conditions. Time before optimal maturity was set at 14 days, assumed yield potential $\left(Y_{P}\right)$ was set at $4,480 \mathrm{~kg} / \mathrm{ha}$, and market type contract prices were as previously described. Although different initial defoliation levels were explored, $20 \%$ was used in this scenario. Potential available yield $\left(P_{Y}\right)$ assuming no additional yield loss related to environmental conditions or harvest operation (e.g., low soil moisture or suboptimal digging and harvest speeds, respectively) (Anco et al. 2019; Fogle et al. 2019) was calculated as

$$
P_{Y}=Y_{P}(1-y M)
$$

with $y$ as estimated from Equation 6 of M2 and $M=$ number of days until optimal maturity. Proportion yield loss at a specified defoliation level was determined with parameters estimated from M1 with state coefficients averaged for generality, with level of defoliation per day calculated with estimated parameters from the second stage of M3, and with $C$ from Equation 7 calculated (5.563, proportional to estimated $\beta_{L}$ and equivalent to using a version of Equation 7 omitting $C$ and setting $\beta_{L}$ equal to 4 per $\beta_{L}=\left[1-y_{0}\right] / y_{0}$, where $y_{0}$ is the constant of integration) to place its $y$-intercept equal to the chosen initial defoliation level (20\%). Accordingly, estimation of $\beta_{L}$ for purposes of second-stage M2 calculations was inconsequential but is included here nonetheless for completeness. Estimated obtainable yield, $E_{Y}$, was calculated as

$$
E_{Y}=P_{Y}-\left(P_{Y} \times Y\right)
$$

where $Y$ is from Equation 1 or 2 for Virginia or runner market type calculations, respectively, at the defoliation level determined as described in Equation 7. Under these assumptions, calculated defoliation did not exceed $95 \%$.

\section{Results}

Yield loss with defoliation. Across the M1 data, yield loss per study ranged from -17.0 to $83.7 \%$ for Virginia market types and -11.3 to $89.0 \%$ for runner market types, with medians of 7.9 and $12.0 \%$, respectively (Fig. 1A). Leaf spot defoliation for Virginia market types ranged from 0 to $99.8 \%$ and from 0.3 to $100 \%$ for runner market types (Fig. 1B). Median defoliation values across datasets were 11.9 and $30.5 \%$ for Virginia and runner market types, respectively.

Equation 1 fitted to the Virginia market type M1 data produced a CCC of 0.900 . This indicated a high degree of reliability for the model in predicting yield loss, and the corresponding response surface was described well by an exponential relationship with increasing defoliation (Fig. 2A and B). Collective reliability of Equations 2 and 3 in predicting yield loss as a function of defoliation for runner market type cultivars was somewhat lower, albeit also generally reliable, with a value of 0.845 . Although Equation 3 similarly produced an exponential response surface for yield loss of runner market type peanut with increasing defoliation, this occurred after $\geq 95 \%$ defoliation. However, yield loss under most defoliation levels $(<95 \%)$ for runner cultivars exhibited a more gradually increasing linear relationship per Equation 2 (Fig. 2C). Errors from both models exhibited a random scatter across observed values (Fig. 2B and D).

For the Virginia market type model, the exponential rate of yield loss related to leaf spot defoliation was estimated at $1.7 \%$ of current loss levels per additional percent defoliation (95\% CI, 1.2 to $2.2 \%$ ). When $\geq 25 \%$ of the canopy was defoliated (95\% CI, 6.6 to $10.6 \%$ ), yield loss was estimated to be different from loss estimated at $5 \%$ defoliation (95\% CI, 2.0 to $6.0 \%$ ). The linear estimate of the yield loss contribution per unit southern stem rot incidence was 0.606 per unit increase (95\% CI, 45.9 to $75.2 \%$ ). Cylindrocladium black rot incidence among the analyzed data contributed to yield loss at the rate of 0.997 per unit increase (95\% CI, 75.1 to $124.3 \%$ ). All estimated parameters were significant (Table 1), with the exception of the coefficient for the fixed effect of North Carolina $(-0.040, P=$ 0.2902). Although this individual parameter was not significant, it was retained in the model along with terms corresponding to other states to represent inclusion of the overall fixed effect of state. State adjustments from South Carolina and Virginia were approximately 2.25 times larger in absolute magnitude and similar among themselves, being -0.091 and -0.089 , respectively.

The runner market type model estimated yield loss to increase at a linear rate of $2.5 \%$ per $10 \%$ increase in defoliation (95\% CI, 2.2 to $2.8 \%$ ) when defoliation was $<95 \%$. When defoliation exceeded $95 \%$, loss was predicted to increase at the rate of $14.7 \%$ (backtransformation of $S_{1}$ ) of current loss levels per additional percent defoliation. Yield loss for runner market type cultivars was estimated to be different from loss estimated at 5\% defoliation at 30\% defoliation (95\% CI, 6.9 to $12.0 \%$ compared with 0.6 to $5.8 \%$ at $5 \%$ defoliation). Southern stem rot levels present in analyzed studies were estimated to contribute to yield loss at the rate of $73.1 \%$ per unit incidence ( $95 \%$ CI, 59.8 to $86.4 \%$ ), with total disease symptom complex (rated in experiments where dedicated southern stem rot ratings were not reported) contributing yield loss at $34.3 \%$ per unit incidence $(95 \%$ CI, 3.7 to $64.8 \%$ ). As with the Virginia market type model, all parameter estimates of the runner market type model were significant, save coefficients for Alabama $(0.005, P=0.7407)$ and South Carolina 
$(-0.026, P=0.5003)$. Mean adjustments corresponding to Florida and Texas were 0.038 and 0.061 , respectively.

Relative yield and defoliation increase over time. Relative rate of yield increase per day among experiments ranged from 0.2 to $3.0 \%$ (Fig. 3), with a median slope of $1.0 \%$. The estimated effect size (M2) for this rate of yield increase was $1.2 \%$ per day (Table 2; 95\% CI, 0.9 to $1.5 \%$ ).

Among experiments included in the M3 first-stage analysis, $\beta_{L}$ estimates ranged from 2.8 to 269.7 with a median of 17.9. Range of $\gamma_{L}$ estimates spanned 0.06 to 0.23 ; median $\gamma_{L}$ across experiments was
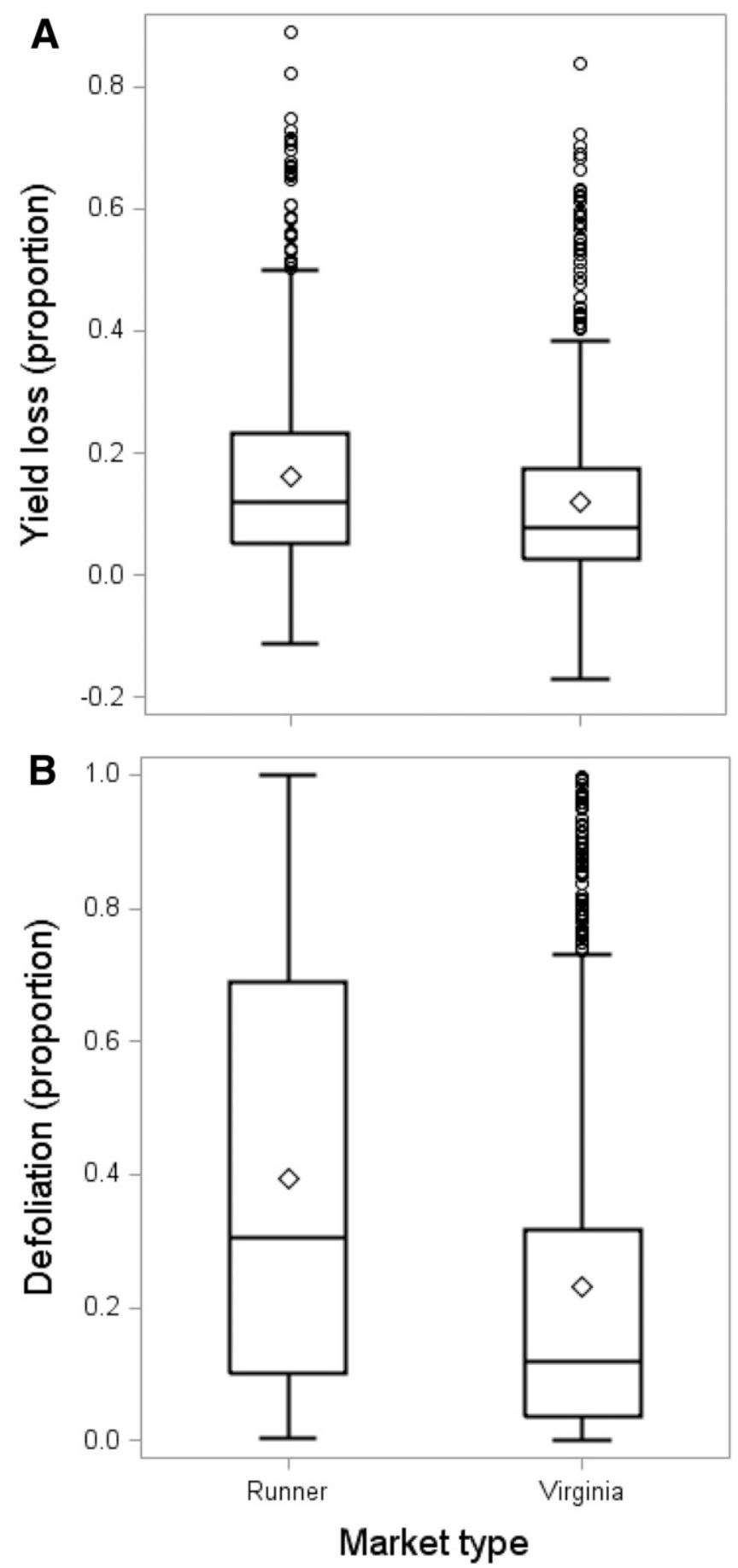

Fig. 1. A, Yield loss and B, defoliation data from studies included in a meta-analysis of the relationship of peanut yield loss and defoliation caused by late or early leaf spot. Means and medians are respectively represented by the open diamond and the solid horizontal line. The first and third quartiles are represented by the lower and upper edges of the box, respectively, whereas the whiskers represent the range of values beyond the interquartile range yet $<1.5$ interquartile ranges.
0.14 (Fig. 4). After the second stage of the M3 analysis, $\beta_{L}$ was estimated at $8.3(95 \% \mathrm{CI}, 3.6$ to 12.9$)$ (Table 3$)$. The effect size pertaining to the rate of defoliation increase over time, $\gamma_{L}$, was estimated at 0.13 (95\% CI, 0.11 to 0.16 ), which corresponds to a linear logit scale increase of $13 \%$.

Yield loss with defoliation in an immature crop. Virginia market type cultivars assumed to reach optimal maturity 14 days after having sustained $20 \%$ defoliation were predicted to reach optimal estimated obtainable yield when defoliation reached $40 \%$ (Table 4). After this point, loss increased faster than yield was predicted to increase. Defoliation during this scenario was predicted to increase from 20 to $60 \%$, and potential available yield $\left(P_{Y}\right)$ was predicted to increase from 85.7 to $100 \%$. The overall $95 \%$ prediction interval for estimated yield value loss was fairly wide, extending from $\$ 150$ to $730 /$ ha at $40 \%$ defoliation. Although digging at the yield increase inflection point of $40 \%$ decreased estimated loss by approximately $\$ 65 /$ ha compared with $\$ 510 /$ ha if dug 14 days prematurely, the prediction interval for loss can be seen to exhibit considerable overlap at various days ahead of optimal maturity (Fig. 5A).

Under the examined parameters for runner market types, the predicted relationship exhibited a gradual decrease in estimated loss from $\$ 490$ to $380 /$ ha (Fig. 5B) as $M$ progressed from 14 to 0 days. During this interval, the proportion yield loss because of defoliation ranged from $6.9 \%$ at $M=14$ to $17.1 \%$ at $M=0$. Taken in context with increasing $P_{Y}$, the rate of $E_{Y}$ increase relative to this rate at $M=14$ decreased from 100 to $71 \%$ after only 4 days, further decreasing to $37 \%$ after an additional 6 days (Table 4) under the assumptions of this scenario. The $95 \%$ PI for predicted loss was narrower than for Virginia market types, being $\$ 110$ to $610 /$ ha at $M=0$ days.

\section{Discussion}

The results of this study contribute to the body of knowledge about peanut yield loss in the presence of late or early leaf spot defoliation for two major market types produced in the United States. To our knowledge, this is the first study to use meta-analysis to describe this relationship in peanut. Carley et al. (2009) estimated the rate of yield loss for mature 'Gregory' peanut to be $23 \mathrm{~kg} / \mathrm{ha}$ (or $0.5 \%$ ) per $1 \%$ increase in defoliation, based on a yield potential of $4,400 \mathrm{~kg} / \mathrm{ha}$. For Virginia market type cultivars in the current study, this was the rate estimated when defoliation was $62 \%$, being lower and greater when defoliation was below or above this amount, respectively. The corresponding instantaneous rate of change of the nonlinear rate of the current study, based on a $4,400 \mathrm{~kg} / \mathrm{ha}$ potential, ranged from $12 \mathrm{~kg} / \mathrm{ha}$ (or $0.27 \%$ ) per $1 \%$ defoliation at $25 \%$ defoliation to $38 \mathrm{~kg} / \mathrm{ha}(0.87 \%)$ per $1 \%$ defoliation at $95 \%$ defoliation. Over 6 years, Jordan et al. (2016) reported the relationship between economic value of Gregory peanut and defoliation to be more confounded, although the economic value of later digging dates generally increased with the number of fungicide applications. Part of this variability was attributed to nontarget Sclerotinia blight incidence and suboptimal digging conditions associated with a calendar-based digging schedule. For the runner market type cultivar 'Florunner,' previous literature has reported a yield loss rate of $57 \mathrm{~kg} / \mathrm{ha}$ per unit defoliation increase (Backman and Crawford, 1984), whereas Nutter and Littrell (1996) estimated Florunner yield losses among individual location-years varying from 33 to $99 \mathrm{~kg} / \mathrm{h}$. The runner market type yield loss rate from the present work was much lower at an equivalent of $11 \mathrm{~kg} / \mathrm{ha}$ per unit defoliation. Differences between these estimates may be because of the number of experiments (realizations) included in the analyses, as well as the current analysis spanning multiple cultivars (9 Virginia market type cultivars and 27 runner market type cultivars) in contrast to several previous reports using a single cultivar. The overall level of leaf spot resistance or tolerance among this group of runner cultivars likely exceeds that of Florunner and could help explain why this study estimated less loss. Although multiple cultivars were included in this analysis, using a relative proportion yield loss scale readily facilitated the integration of data from cultivars and growing conditions with varying yield potentials and subsequent generalization of results for interpretability in other situations. 
Although respective information was not reported in the data considered here, peanut peg strength has been reported to vary by cultivar (Johnson George et al. 1988; Sorensen et al. 2017; Thomas et al. 1983 ) and market type, with field losses proportional to the ratio of peg strength to projected pod surface area (Troeger et al. 1976). The greater pod size of Virginia market types consequently puts more strain on available peg strength, with the effect being exacerbated under conditions of increased defoliation and weakened or deteriorated pegs (Bourgeois et al. 1991; Knauft et al. 1988). These considerations add biologically plausible context to the relative (exponential) rate of yield loss described by Equation 1, translating into greater losses at elevated defoliation levels. When asymptomatic pods were assessed, Chapin and Thomas (2005) reported no differences in 'NC-V11' peg strength between plants with severe defoliation and those with no defoliation. However, Chapin and Thomas (2005) also noted a much greater prevalence of deteriorated pegs overall on peanut affected by leaf spot, for which peg strength measurements were not conducted. Thus, the overall distribution of peg strength may still be weaker under severe defoliation, although further work is needed to quantitatively verify this.
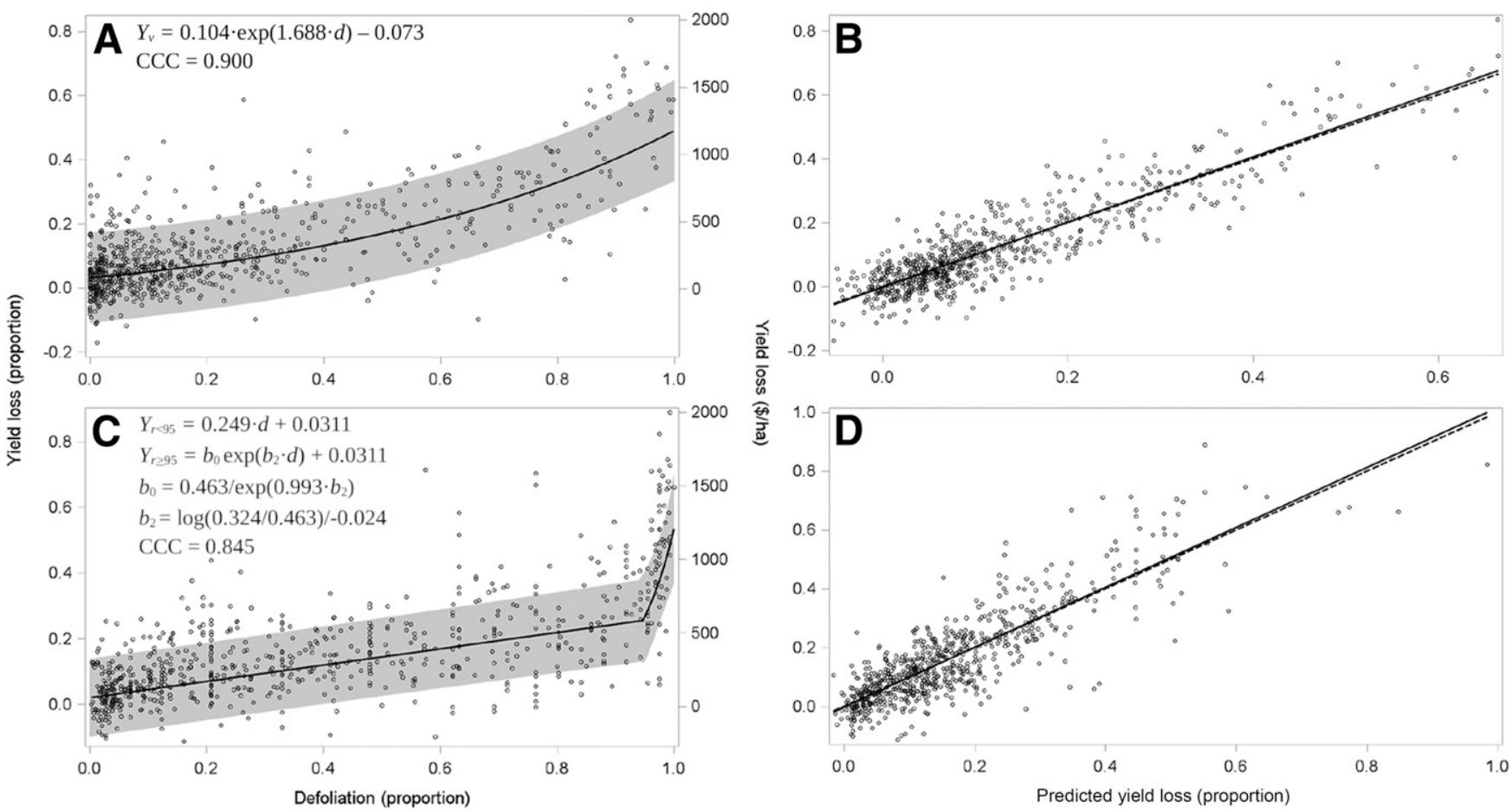

Fig. 2. Peanut yield loss as a metaregression of defoliation caused by late or early leaf spot for A, Virginia or C, runner market type cultivars. Bands are $95 \%$ prediction intervals. Yield loss (in $\$ / \mathrm{ha}$ ) calculations assumed $4,480 \mathrm{~kg} / \mathrm{ha}$ yield potential and contract values of $\$ 500$ or $\$ 470 / 1,000 \mathrm{~kg}$ for Virginia or runner market types, respectively. Observed versus predicted proportion yield loss for meta-analytic models fitted to B, Virginia or D, runner market type cultivars. Solid lines are fitted regression lines, whereas dashed lines represent the line of perfect agreement. Predictions were calculated with the average of state adjustments from the mean.

Table 1. Parameter estimates from a meta-analysis of proportion peanut yield loss after defoliation caused by late or early leaf spot ${ }^{\mathrm{a}}$

\begin{tabular}{|c|c|c|c|c|c|c|c|c|}
\hline Market type & Parameter & Estimate & SE & $\mathbf{C I}_{\mathbf{L}}$ & $\mathbf{C I}_{\mathbf{U}}$ & $\mathbf{P I}_{\mathbf{L}}$ & $\mathbf{P I}_{\mathbf{U}}$ & $P$ \\
\hline \multirow[t]{9}{*}{ Virginia } & $b_{0}$ & 0.104 & 0.029 & 0.046 & 0.162 & -0.029 & 0.238 & $<0.0001$ \\
\hline & $b_{1}$ & 1.688 & 0.240 & 1.209 & 2.168 & 1.194 & 2.183 & $<0.0001$ \\
\hline & $b_{2}$ & 0.606 & 0.073 & 0.459 & 0.752 & 0.416 & 0.795 & $<0.0001$ \\
\hline & $b_{3}$ & 0.997 & 0.123 & 0.751 & 1.243 & 0.723 & 1.271 & $<0.0001$ \\
\hline & $\beta_{\mathrm{NC}}$ & -0.040 & 0.0377 & -0.116 & 0.035 & -0.182 & 0.102 & 0.2902 \\
\hline & $\beta_{\mathrm{SC}}$ & -0.091 & 0.034 & -0.159 & -0.023 & -0.229 & 0.047 & 0.0097 \\
\hline & $\beta_{\mathrm{VA}}$ & -0.089 & 0.037 & -0.163 & -0.014 & -0.230 & 0.0530 & $<0.0001$ \\
\hline & $s_{u}{ }^{2}$ & 0.0036 & 0.00075 & 0.0021 & 0.0051 & - & - & $<0.0001$ \\
\hline & $s_{\varepsilon}^{2}$ & 0.0042 & 0.00022 & 0.0037 & 0.0047 & - & - & $<0.0001$ \\
\hline \multirow[t]{11}{*}{ Runner } & $S_{1}$ & 0.463 & 0.025 & 0.414 & 0.513 & 0.358 & 0.569 & $<0.0001$ \\
\hline & $b_{1}$ & 0.249 & 0.014 & 0.220 & 0.278 & 0.152 & 0.346 & $<0.0001$ \\
\hline & $S_{2}$ & 0.324 & 0.015 & 0.294 & 0.355 & 0.227 & 0.422 & $<0.0001$ \\
\hline & $b_{3}$ & 0.731 & 0.066 & 0.598 & 0.864 & 0.568 & 0.893 & $<0.0001$ \\
\hline & $b_{4}$ & 0.343 & 0.151 & 0.037 & 0.648 & 0.024 & 0.662 & 0.0287 \\
\hline & $\beta_{\mathrm{AL}}$ & 0.005 & 0.014 & -0.024 & 0.034 & -0.092 & 0.102 & 0.7407 \\
\hline & $\beta_{\mathrm{FL}}$ & 0.038 & 0.012 & 0.013 & 0.063 & -0.058 & 0.134 & 0.0036 \\
\hline & $\beta_{\mathrm{SC}}$ & -0.026 & 0.039 & -0.104 & 0.052 & -0.148 & 0.095 & 0.5003 \\
\hline & $\beta_{\mathrm{TX}}$ & 0.061 & 0.027 & 0.007 & 0.115 & -0.046 & 0.168 & 0.0267 \\
\hline & $s_{u}^{2}$ & 0.0021 & 0.0006 & 0.0009 & 0.0033 & - & - & 0.0009 \\
\hline & $s_{\varepsilon}^{2}$ & 0.0070 & 0.0004 & 0.0062 & 0.0077 & - & - & $<0.0001$ \\
\hline
\end{tabular}

\footnotetext{
${ }^{\mathrm{a}} \mathrm{CI}_{\mathrm{L}}$, estimated lower $95 \%$ confidence interval; $\mathrm{CI}_{\mathrm{U}}$, estimated upper $95 \%$ confidence interval; $\mathrm{PI}_{\mathrm{L}}$, estimated lower $95 \%$ prediction interval; $\mathrm{PI}_{\mathrm{U}}$, estimated upper
} 95\% prediction interval. Prediction intervals were not calculated for covariance parameters $(-)$. 
For simplicity and because of restrictions imposed by available data, calculations involving yield and loss for an immature peanut crop assumed the relationship between rate of daily yield increase and canopy condition (defoliation) to be independent. This is possibly a reasonable approximation at lower levels of defoliation, but the appropriateness becomes questionable as defoliation levels increase (Aquino et al. 1992; Bourgeois et al. 1991; Nutter and Littrell 1996; Singh et al. 2011). Conceivably, if defoliation levels $>25 \%$ resulted in yield loss differences compared with negligible defoliation (e.g., 5\%), these amounts could be anticipated to begin to affect the rate of potential yield increase in an otherwise healthy crop, given enough accumulated time, as linear relationships between pod yield and accumulated disease or healthy canopy area have been reported (Aquino et al. 1992; Nutter and Littrell 1996; Singh et al. 2011). Thus, although the parameters (e.g., from M2) used for predictions with an immature runner market type suggested they could absorb $60 \%$ defoliation and still increase possible yield potential (before yield loss at harvest because of defoliation is factored in) at the same rate as a crop with $0 \%$ defoliation, this is probably an optimistic assumption. A possible implication is that yield development for runner market type peanut may proceed at a slower rate under an increasingly diminished functional canopy. For Virginia type peanut, the predicted $E_{Y}$ inflection point of $40 \%$ defoliation probably is conservative enough to be robust to a potentially simplified rate of potential yield increase. Still, these estimates involving immature peanut serve only as a reference to explore simultaneous rates of potential yield increase, disease defoliation progression, and subsequent increased proportion yield loss over time.

Another possibility that warrants consideration is how the atharvest yield loss estimates modeled as a function of end-of-season defoliation, to a certain extent, implicitly include accumulated effects of a diseased canopy. Plausibility of this consideration is contributed by the fact that although the absolute rate of leaf spot defoliation progression varies because of factors including sources of available inoculum, environmental conditions, and host susceptibility, it still takes a certain amount of time to develop. From two separate years in Florida, Bourgeois et al. (1991) reported no differences in

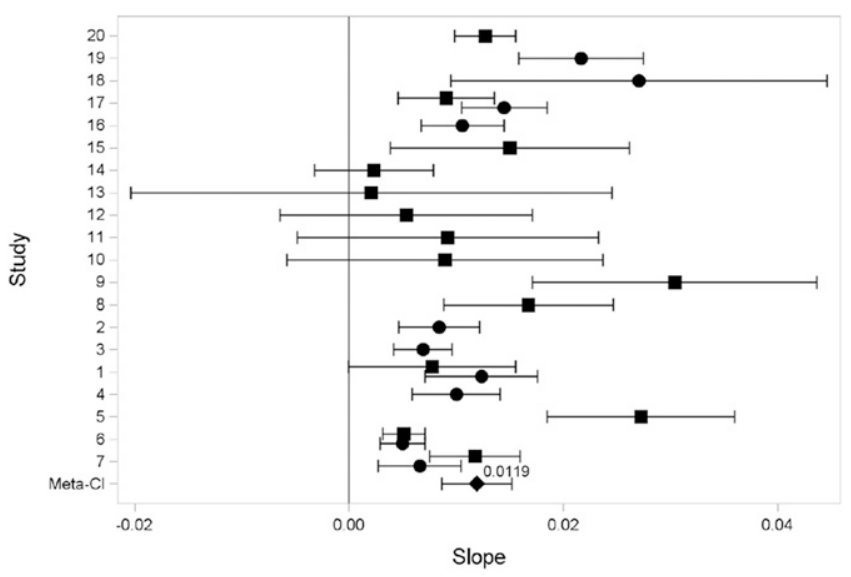

Fig. 3. Forest plot of study data included in a meta-analysis of the proportion rate (slope) of relative yield increase toward a relative optimum per day. Slopes corresponding to Virginia or runner market type cultivars appear as squares and circles, respectively, with the slope effect size estimated from the meta-analysis appearing as a diamond. Error bars are $95 \%$ confidence intervals. accumulated pod yield between Florunner treated with fungicides or nontreated until defoliation at harvest exceeded $75 \%$. These yield differences were approximately 30 days after corresponding leaf area index began to differ, at which time defoliation levels were 20 to $45 \%$. In the same study, pods harvested 14 days earlier than approximate optimal maturity from peanut with substantial defoliation corroborated the yield loss estimated from Equation 2 fairly closely, corresponding to $26.4 \%$ loss at approximately $85 \%$ defoliation (Bourgeois et al. 1991; increase over 5 days from $78 \%$ defoliation reported, with estimation according to M3) compared with the predicted loss of $23 \%$ (95\% PI, 11 to 35\%) (Equation 2). The agreement between data reported from Bourgeois et al. (1991) and estimated loss from the current analysis decreased as defoliation levels approached $95 \%$ (increase over 5 days from $90 \%$ defoliation reported, with estimation according to M3): 58\% loss previously reported compared with the predicted $26 \%$ (95\% PI, 13 to $41 \%$ ). This disagreement might be because of actual defoliation having exceeded the $95 \%$ estimated from the additional 5 days after the previous assessment reported in Bourgeois et al. (1991). Keeping this in perspective without diminishing the importance of precision, if a field is $95 \%$ defoliated, primary concerns are typically not centered around how precise our predicted estimates of yield loss might be, because overall losses would be anticipated to be considerable. Three days after defoliation reached $100 \%$, however, observed yield loss in that same study fell within the $95 \%$ PI for loss at $100 \%$ defoliation: $69 \%$ observed compared with 37 to $70 \%$. Nevertheless, as indicated from the present analysis, runner market type cultivars appear to be able to sustain more defoliation than Virginia market type cultivars while losing yield at a more gradual rate when defoliation is $<95 \%$. For both market types, overall losses at the upper end of $100 \%$ defoliation closely mirrored the common 50\% loss reported previously (KokalisBurelle et al. 1997), with 95\% PI spanning 33 to $65 \%$ for Virginia types and 37 to $70 \%$ for runner types.

The current analyses used defoliation on a 0 to $100 \%$ scale. Another popular method to quantify leaf spot diseases that has been used for many years is the Florida 1 to 10 Scale (Chiteka et al. 1988). Election to use defoliation, including converting Florida 1 to 10 Scale values into defoliation, centered on the properties of a scale that readily allowed continuous calculations and exhibited continuity between scale values. The Florida 1 to 10 Scale has several desirable features in general, including ease of use, phenomenological interpretability, and capacity to document the phases of a leaf spot epidemic from initial lesions to complete defoliation and death. Nevertheless, although the direct estimation of percentage defoliation may benefit from practice or calibration, visual estimates can describe approximately how much defoliation has occurred in a given canopy. Other studies have suggested percentage severity is of more direct utility to disease quantification and yield loss estimates (Singh et al. 2011; Waggoner and Berger 1987), whereas yet other studies report a looser functional relationship between severity and yield reduction overall (Bastiaans 1991; Bergamin Filho et al. 1997; de Jesus et al. 2001). However, severity is often more cumbersome and time consuming to rate; therefore, severity may be less approachable for general use, save for potentially automated sensor-based methods. Translations of the interval-based nature of the Florida 1 to 10 Scale were seen in the residuals of the runner market type model fit (data not shown). From the studentized residuals, data originally reported as percentage defoliation ( $n=216$ observations) ranged from -3.45 to 1.88 , with lower and upper quartiles of -0.41 and 0.44 , respectively. From studies with data originally reported on the Florida 1 to 10 Scale $(n=515$ observations), residuals ranged from -3.90 to 4.02 , with lower and

Table 2. Parameter estimates from a meta-analysis of relative peanut yield increase toward a relative optimum in relation to increasing time (days) ${ }^{\mathrm{a}}$

\begin{tabular}{lllllll}
\hline Parameter & Estimate & SE & CI $_{\mathbf{L}}$ & CI $_{\mathbf{U}}$ & PI $_{\mathbf{L}}$ & \multicolumn{1}{c}{$\boldsymbol{P}$} \\
\hline$\zeta$ & 0.0119 & 0.0015 & 0.0086 & 0.0152 & -0.0011 & 0.0250 \\
$s_{u}{ }^{2}$ & 0.000034 & 0.000016 & 0.000013 & 0.000088 & $<0.0001$ \\
\hline
\end{tabular}

a $\mathrm{CI}_{\mathrm{L}}$, estimated lower $95 \%$ confidence interval; $\mathrm{CI}_{\mathrm{U}}$, estimated upper $95 \%$ confidence interval; $\mathrm{PI}_{\mathrm{L}}$, estimated lower $95 \%$ prediction interval; $\mathrm{PI}_{\mathrm{U}}$, estimated upper 95\% prediction interval. Prediction intervals were not calculated for covariance parameters $(-)$. 
upper quartiles at -0.64 and 0.52 , respectively. These results illustrate instances of increased model error associated with the analyzed data originally reported on the Florida 1 to 10 Scale (a byproduct of transformation from discretized intervals for an otherwise continuous variable), although it should also be noted that the overall model fit was robust to this variation per the random scatter about the respective predicted-observed line and the CCC value being 0.845 . The

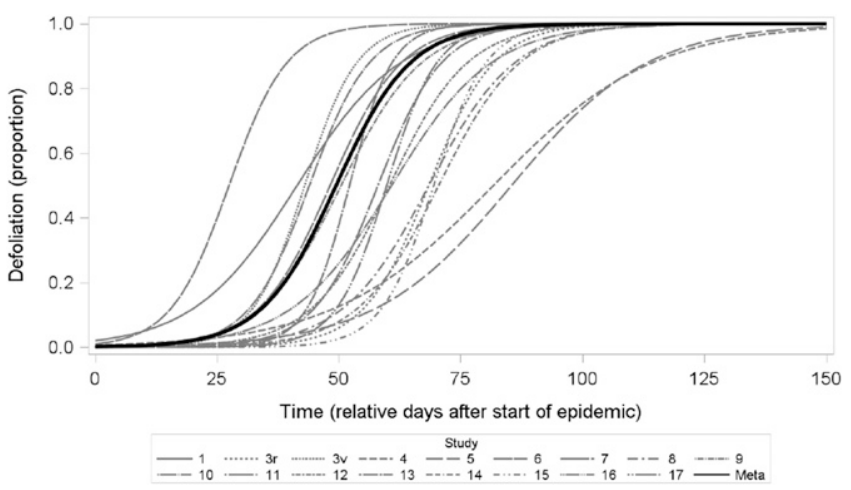

Fig. 4. Peanut defoliation curves from studies included in a meta-analysis as a function of the number of increasing days relative to the start of established late or early leaf spot epidemic under conditions conducive to rapid disease development (e.g., no fungicide protection and a susceptible cultivar). The bold line represents the curve for the combined meta-analysis of 16 studies. evident robustness is probably contributed in part to the sheer number of data points included in the analysis and the model specification. Conversely, with the Virginia market type data, six times as many observations were reported per percent defoliation compared with the Florida 1 to 10 Scale (638 vs. 105, respectively). Therefore, the range of studentized residuals was greater for observations reported on the defoliation scale compared with the Florida 1 to 10 Scale $(-3.41$ to 3.31 compared with -2.43 to 2.24 , respectively, with corresponding lower and upper quartiles ranging from -0.67 to 0.57 and -0.48 to 0.37 ). This is probably simply a function of more data having been reported with the defoliation scale. Overall, the observed ranges in studentized residuals for both market type models were reasonable and did not result in removal of data from the analysis.

The estimation of the fixed effect coefficients for state was conducted primarily to facilitate the overall model fitting process. Thus, phenomenological interpretation of these values here is tempered. Estimated differences could be contributed by soil type, physical methods of experiment conduct and harvest, or an interaction thereof. Therefore, an attempt to frame these coefficients explicitly in terms of biologically based phenomena directly tied to geographic location is avoided. Data supporting the generalization of results over states include how, when significant, state coefficients per market type differed by $<3 \%$.

Another factor beyond the scope of this study was the relationship between the time of disease onset and time of harvest. It is plausible that the same amount of defoliation rapidly occurring just before harvest may have less of an impact on yield loss, in turn giving the producer greater flexibility in the decision to dig, compared with the

Table 3. Parameter estimates from two univariate meta-analyses for logistic model parameters $\left(\beta_{L}\right.$ and $\left.\gamma_{L}\right)$ of proportion peanut defoliation caused by late or early leaf spot with increasing time (days) ${ }^{\mathrm{a}}$

\begin{tabular}{lcccccc}
\hline Parameter & Estimate & $\mathbf{S E}$ & $\mathbf{C I}_{\mathbf{L}}$ & $\mathbf{C I}_{\mathbf{U}}$ & $\mathbf{P I}_{\mathbf{L}}$ & $\mathbf{P I}_{\mathbf{U}}$ \\
\hline$\beta_{L}$ & 8.263 & 1.792 & 3.634 & 12.891 & -4.147 & 20.672 \\
$s_{u \beta L^{2}}$ & 19.878 & 16.191 & 4.064 & 101.99 & - & 0.0060 \\
$\gamma_{L}{ }_{u \gamma L^{2}}$ & 0.130 & 0.012 & 0.106 & 0.155 & 0.038 & 0.223 \\
\hline
\end{tabular}

${ }^{\text {a }} \mathrm{CI}_{\mathrm{L}}$, estimated lower $95 \%$ confidence interval; $\mathrm{CI}_{\mathrm{U}}$, estimated upper $95 \%$ confidence interval; $\mathrm{PI}_{\mathrm{L}}$, estimated lower $95 \%$ prediction interval; $\mathrm{PI}_{\mathrm{U}}$, estimated upper 95\% prediction interval. Prediction intervals were not calculated for covariance parameters (-).

Table 4. Estimated levels of defoliation, yield potential, and loss because of defoliation, estimated obtainable yield, and rate of yield increase change over time for peanuts

\begin{tabular}{|c|c|c|c|c|c|c|c|c|}
\hline \multirow[b]{2}{*}{ Market type } & \multirow[b]{2}{*}{$M^{\mathbf{a}}$} & \multirow[b]{2}{*}{ Defoliation $(\%)^{\mathbf{b}}$} & \multirow[b]{2}{*}{$P_{Y}(\%)^{\mathrm{c}}$} & \multirow[b]{2}{*}{$Y(\%)^{d}$} & \multirow[b]{2}{*}{$E_{Y}(\mathrm{~kg} / \mathrm{ha})^{\mathrm{e}}$} & \multirow[b]{2}{*}{$\operatorname{Loss}(\$ / h a)^{\mathbf{f}}$} & \multicolumn{2}{|c|}{$\mathrm{d} E_{Y} / \mathrm{dt}^{\mathrm{g}}$} \\
\hline & & & & & & & $(\mathrm{kg} / \mathrm{ha} / \mathrm{d})$ & $(\%)$ \\
\hline \multirow[t]{8}{*}{ Virginia } & 14 & 20.0 & 83.3 & 7.3 & 3,462 & 507 & 26.5 & - \\
\hline & 12 & 24.5 & 85.7 & 8.4 & 3,517 & 479 & 20.4 & 77.0 \\
\hline & 10 & 30.0 & 88.1 & 9.9 & 3,559 & 459 & 13.2 & 49.8 \\
\hline & 8 & 35.3 & 90.4 & 11.6 & 3,584 & 446 & 4.8 & 18.1 \\
\hline & 6 & 41.5 & 92.8 & 13.7 & 3,593 & 442 & -4.4 & -16.6 \\
\hline & 4 & 47.9 & 95.2 & 16.1 & 3,582 & 447 & -13.9 & -52.5 \\
\hline & 2 & 54.4 & 97.6 & 18.8 & 3,553 & 461 & -22.9 & -86.4 \\
\hline & 0 & 60.8 & 100 & 21.8 & 3,507 & 484 & -30.5 & -115.1 \\
\hline \multirow[t]{8}{*}{ Runner } & 14 & 20.0 & 83.3 & 6.9 & 3,432 & 493 & 29.8 & - \\
\hline & 12 & 24.5 & 85.7 & 8.0 & 3,487 & 467 & 25.6 & 85.9 \\
\hline & 10 & 30.0 & 88.1 & 9.3 & 3,534 & 445 & 21.2 & 71.1 \\
\hline & 8 & 35.3 & 90.4 & 10.7 & 3,572 & 427 & 17.1 & 57.4 \\
\hline & 6 & 41.5 & 92.8 & 12.3 & 3,603 & 412 & 13.6 & 45.6 \\
\hline & 4 & 47.9 & 95.2 & 13.9 & 3,627 & 401 & 10.9 & 36.6 \\
\hline & 2 & 54.4 & 97.6 & 15.5 & 3,647 & 392 & 9.4 & 31.5 \\
\hline & 0 & 60.8 & 100 & 17.1 & 3,666 & 383 & 9.1 & 30.5 \\
\hline
\end{tabular}

a $M$, number of days until optimal maturity.

b Percentage defoliation caused by late or early leaf spot predicted as a function of time after a meta-analysis (M3).

${ }^{\mathrm{c}} P_{Y}$, possible yield potential based on meta-analysis (M2).

${ }^{\mathrm{d}} Y$, yield loss predicted because of defoliation caused by late or early leaf spot based on meta-analysis (M1).

${ }^{\mathrm{e}} E_{Y}$, estimated obtainable yield at harvest after defoliation assuming $4,480 \mathrm{~kg} / \mathrm{ha}$ yield potential at $M=0$.

${ }^{\mathrm{f}}$ Loss assuming contract prices of $\$ 500 / 1,000 \mathrm{~kg}$ and $\$ 470 / 1,000 \mathrm{~kg}$ for Virginia and runner market types, respectively.

${ }^{\mathrm{g}} \mathrm{d} E_{Y} / \mathrm{dt}$, instantaneous rate of change in $E_{Y}$ per unit time; \% values are relative to $\mathrm{d} E_{Y} / \mathrm{dt}$ at $M=14$. 
same amount of disease having occurred earlier (as in Jordan et al. 2016), with this latter example potentially affecting the physiology and development of the plant for a longer period of time. This is a confounded issue, because leaf spot diseases typically continue to progress over time, assuming conditions reasonably favorable for general growth of the peanut plant itself.

Planning and resultant profitability of peanut harvest decisions depend on many interrelated factors. Among these are cultivar, crop maturity, current and accumulated vine health (including previous exposure to drought stress), weather conditions (e.g., precipitation and temperature including frost) before and after inversion, soil type and condition, acreage and equipment logistics, and digging practices (Anco et al. 2019; Chapin and Thomas 2005; Fogle et al. 2019; Jordan et al. 2018b; Kemerait et al. 2018; Sorensen et al. 2017; USDA FSA 2018). Therefore, the best way to use the results of the current study may be as rough (flexible) rules, taking into consideration all other relevant information on the crop, field, and weather at and around the time of harvest. These results indicated that yield loss for mature Virginia market type cultivars became significant (compared with 5\% defoliation) once defoliation reached $\geq 25 \%$, whereas yield loss of runner market types at crop maturity became significant at $\geq 30 \%$ defoliation. For immature crops, although there was considerable variation in the prediction interval, it was estimated that, overall, Virginia types would start to lose more yield through associated pod loss than they would gain through maturity development once defoliation exceeds $40 \%$. Runner market type cultivars appear to be able to tolerate greater amounts of defoliation, with immature crops probably able to sustain $50 \%$ defoliation before further yield loss exceeds gains from additional maturity development. Although the examined scenario with an immature runner crop

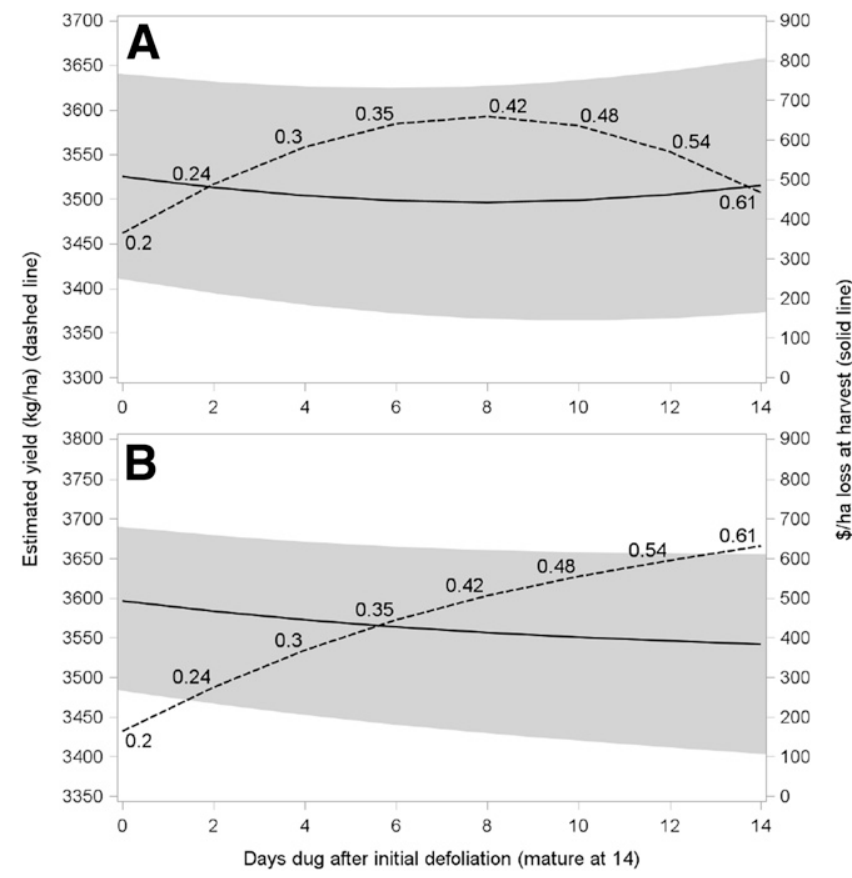

Fig. 5. Estimated obtainable yield (in kg/ha; dashed line) and harvest value loss (in $\$ /$ ha; solid line) at digging after increasing time (days) in the presence of defoliation (displayed decimals) caused by late or early leaf spot for A, Virginia and B, runner market type cultivars. Estimates of relationships of peanut yield loss with increasing defoliation, proportion yield increase with time, and rate of defoliation increase with time were obtained through meta-analyses. Bands represent $95 \%$ prediction intervals based on estimated yield loss with increasing defoliation (rates of yield potential and defoliation increase with time held constant). Calculations assumed $4,480 \mathrm{~kg} / \mathrm{ha}$ yield potential; contract values of $\$ 500$ or $\$ 470 / 1,000 \mathrm{~kg}$ for Virginia or runner market types, respectively; potential yield increase per day independent of present or past disease accumulation; optimal yield maturity occurring on day 14; conditions favorable for yield and defoliation increase; and a lack of additional harvest losses from adverse conditions (e.g., excessive soil moisture, suboptimal equipment operation). suggested yield loss to continue to decrease at $60 \%$ defoliation, albeit at an increasingly diminishing rate, a more conservative cutoff of approximately $50 \%$ is adopted here to acknowledge the assumptions of this portion of the current work. Based on these scenario results, those of Bourgeois et al. (1991), and that of Supplementary Table S2, a threshold of $50 \%$ defoliation appears reasonable for digging runner type peanut before optimal maturity, all other factors assumed constant. Additional data on analogous early digging under a range of conditions could tailor this threshold to specific situations (e.g., dryland fields with high clay content across varying defoliation and soil moisture conditions). Caution must be warranted with this threshold (and arguably others), because it references point estimate losses assuming the field is dug at this level of defoliation. Depending on the size of the field, equipment availability and reliability, weather, and other conditions, digging may need to be initiated at a time before $50 \%$ defoliation.

Again, such situations favor the flexible interpretation of these thresholds as rough rules. The wide prediction intervals of these predictions emphasize the importance of the aforementioned factors in conjunction with defoliation to reduce overall harvest losses. In the presence of defoliation, decisions to dig under more favorable conditions may help reduce overall losses, although the interactions of these possible factors make it difficult to generalize a set number of days surrounding a targeted digging decision when favorable conditions should be identified and considered for all situations. Variability in weather forecasts only adds complexity to the system. Along these lines, although individual estimates compared with previous studies may have differed, a common thread among the relevant literature is corroboration of the importance of effective disease management programs to protect yield potential and economic value (Backman and Crawford 1984; Bourgeois et al. 1991; Jordan et al. 2016; Knauft et al. 1988; Nutter and Littrell 1996; Singh et al. 2011). With these considerations in mind, the results of this study are useful as a tool to help guide management decisions concerning when to dig a peanut crop in the presence of defoliation caused by late or early leaf spot. Similarly, the guidelines proposed herein are useful to growers in years when frequent or abundant late-season rainfall prevents timely fungicide applications, consequently increasing defoliation before inversion.

In summary, this work examined results from a series of studies from the southeast and Virginia-Carolina regions of the United States to describe relationships of peanut yield loss with defoliation caused by late or early leaf spot for Virginia and runner market type cultivars. Significant yield losses began to occur with mature Virginia and runner market type cultivars when defoliation reached 25 and $30 \%$, respectively. Before optimal peanut maturity, defoliation thresholds to minimize economic yield loss were estimated at $40 \%$ for Virginia market types and $50 \%$ for runner market types. These results and thresholds provide helpful information for determining optimal digging times for peanut fields with advanced infections of late or early leaf spot. As discussed above, these thresholds should be considered alongside relevant information about abiotic and biotic factors that affect peanut digging and harvest, with particular attention to weather and digging conditions.

\section{Acknowledgments}

We thank Dr. Jay Chapin for previous work conducted in South Carolina. Technical Contribution no. 6791 of the Clemson University Experiment Station.

\section{Literature Cited}

Anco, D., Thomas, J. S., Marshall, M., Kirk, K. R., and Smith, N. 2019. Peanut money-maker 2019 production guide, Circular 588. Clemson University Extension, Clemson, SC

Anco, D. J., Madden, L. V., and Ellis, M. A. 2013. Effects of temperature and wetness duration on the sporulation rate of Phomopsis viticola on infected grape canes. Plant Dis. 97:579-589.

Anco, D. J., Poole, G. H., and Gottwald, T. R. 2014. Effects of postharvest treatments on recovery of Xanthomonas citri subsp. citri in infected grapefruit leaves. Crop Prot. 62:115-123.

Anco, D. J., and Thomas, J. S. 2018. Evaluation of peanut fungicides and two varieties for disease management, 2016. PDMR. 12:CF160. 
Anco, D. J., Thomas, J. S., and Hiers, J. B. 2018. Evaluation of registered and unregistered fungicides for peanut disease management, 2017. PDMR. 12:CF147.

Aquino, V. M., Shokes, F. M., Berger, R. D., Gorbet, D. W., and Kucharek, T. A. 1992. Relationships among late leafspot, healthy leaf area duration, canopy reflectance, and pod yield of peanut. Phytopathology 82:546-552.

Backman, P. A., and Crawford, M. A. 1984. Relationship between yield loss and severity of early and late leafspot diseases of peanut. Phytopathology 74:1101-1103.

Barocco, R., Beckham, K., Elwakil, W., Stern, P., Shukar, E., Soria, P. S., and Dufault, N. S. 2017a. Comparison of peanut disease management programs with Abound in-furrow, Elatus, and Alto in Florida, 2016. PDMR. 11:FC074.

Barocco, R., Beckham, K., Elwakil, W., Stern, P., Shukar, E., Soria, P. S., and Dufault, N. S. 2017b. Evaluation of in-furrow Velum Total and early season Propulse applications for peanut disease and thrips control in Florida, 2016. PDMR. 11:FC076.

Bastiaans, L. 1991. Ratio between virtual and visual lesion size as a measure to describe reduction in leaf photosynthesis of rice due to leaf blast. Phytopathology 81:611-615.

Bergamin Filho, A., Carneiro, S. M. T. P. G., Godoy, C. V., Amorim, L., Berger, R. D., and Hau, B. 1997. Angular leaf spot of Phaseolus beans: Relationship between disease, healthy leaf area, and yield. Phytopathology 87:506-515.

Boote, K. J. 1982. Growth stages of peanut (Arachis hypogaea L.). Peanut Sci. 9:35-40.

Bourgeois, G., Boote, K. J., and Berger, R. D. 1991. Growth, development, yield, and seed quality of Florunner peanut affected by late leaf spot. Peanut Sci. 18:137-143.

Campbell, H., Hagan, A. K., Bowen, K. L., Pegues, M., and Jones, J. 2018c. Evaluation of chlorothalonil alternatives for peanut disease control in southwest Alabama, 2017. PDMR. 12:CF091.

Campbell, H., Hagan, A. K., Bowen, K. L., Pengues, M., and Jones, J. 2017a. Evaluation of chlorothalonil alternatives for peanut disease control in southwest Alabama, 2016. PDMR. 11:FC071.

Campbell, H., Hagan, A. K., Bowen, K. L., Pengues, M., and Jones, J. 2017b. Evaluation of Elatus 45WG and A19649 for peanut disease control in southwest Alabama, 2016. PDMR. 11:FC070.

Campbell, H., Hagan, A. K., Bowen, K. L., Pengues, M., and Jones, J. 2017c. Evaluation of Mazinga and experimental fungicides for peanut disease control in southwest Alabama, 2016. PDMR. 11:FC069.

Campbell, H., Hagan, A. K., Bowen, K. L., Pengues, M., and Jones, J. 2018d. Evaluation of Elatus 45WG and Miravis for peanut disease control in southwest Alabama, 2017. PDMR. 12:CF093.

Campbell, H., Hagan, A. K., Bowen, K. L., Pengues, M., and Jones, J. 2018e. Evaluation of experimental fungicides for disease control on peanut in southwest Alabama, 2017. PDMR. 12:CF090.

Campbell, H., Hagan, A. K., Bowen, K. L., Pengues, M., and Jones, J. $2018 \mathrm{f}$. Evaluation of Mazinga, Arius ADV, and Brixen for peanut disease control in southwest Alabama, 2017. PDMR. 12:CF092.

Campbell, H., Hagan, A. K., Bowen, K. L., and Wells, L. 2018a. Evaluation of chlorothalonil alternatives for peanut disease control in southeast Alabama, 2017. Auburn University, Auburn, AL.

Campbell, H., Hagan, A. K., Bowen, K. L., and Wells, L. 2018b. Evaluation of new and experimental products for peanut disease control in southeast Alabama, 2017. PDMR. 12:CF094.

Cantonwine, E. G., Culbreath, A. K., and Stevenson, K. L. 2007. Effects of cover crop residue and preplant herbicide on early leaf spot of peanut. Plant Dis. 91: 822-827.

Carley, D. S., Jordan, D. L., Shew, B. B., Sutton, T. B., Dharmasri, C., and Brandenburg, R. L. 2009. Influence of digging date and fungicide program on canopy defoliation and pod yield of peanut (Arachis hypogaea L.). Peanut Sci. 36:77-84.

Carter, E. T., Rowland, D. L., Tillman, B. L., Erickson, J. E., Grey, T. L., GillettKaufman, J. L., and Clark, M. W. 2017. Pod maturity in the shelling process. Peanut Sci. 44:26-34.

Chapin, J. W., and Thomas, J. S. 2005. Effect of fungicide treatments, pod maturity, and pod health on peanut peg strength. Peanut Sci. 32:119-125.

Chiteka, Z. A., Gorbet, D. W., Shokes, F. M., Kucharek, T. A., and Knauft, D. A. 1988. Components of resistance to late leaf spot in peanut I. Levels of variability-implications for selection. Peanut Sci. 15:25-30.

Culbreath, A. K., Brenneman, T. B., Kemerait, R. C., Jr., Stevenson, K. L., and Anco, D. J. 2019. Combinations of elemental sulfur with demethylation inhibitor fungicides for management of late leaf spot (Nothopassalora personata) of peanut. Crop Prot. 125:104911

de Jesus, W. C., Jr., do Vale, F. X. R., Coelho, R. R., Hau, B., Zambolim, L., Costa, L. C., and Bergamin Filho, A. 2001. Effects of angular leaf spot and rust on yield loss of Phaseolus vulgaris. Phytopathology 91:1045-1053.

Douglas, M. H., O'Brien, G. K., Marois, J. J., and Wright, D. L. 2010. Evaluation of foliar fungicides for the control of peanut diseases at the NFREC, Quincy, FL, 2009. PDMR. 4:FC028.

Douglas, M. H., O'Brien, G. K., Marois, J. J., and Wright, D. L. 2011. Evaluation of foliar fungicides for the control of peanut diseases at the NFREC, Quincy, FL, 2010. PDMR. 5:FC100.

Douglas, M. H., O'Brien, G. K., Marois, J. J., and Wright, D. L. 2012. Evaluation of foliar fungicides for the control of peanut diseases at the NFREC, Quincy, FL, 2011. PDMR. 6:FC004

Fogle, B. B., Kirk, K., White, W., Peele, J., Anco, D., Smith, N., and Plumblee, M. 2019. Yield loss and grade effects of peanut combine speed settings. ASABE paper no. 1901725. ASABE, St. Joseph, MI.
George, S., Douglas, M. H., O’Brien, G. K., Marois, J. J., and Wright, D. L. 2014 Evaluation of fungicides for the control of peanut diseases at the NFREC, Quincy, FL, 2013. PDMR. 8:FC269.

Hagan, A. K., Campbell, H. L., Bowen, K. L., Pengues, M., and Jones, J. 2018c. Disease and yield response of runner peanut cultivars to fungicide input level in southwest Alabama, 2017. PDMR. 12:CF031.

Hagan, A. K., Campbell, H. L., Bowen, K. L., Pengues, M., and Jones, J. 2018d Efficacy and yield response of two peanut cultivars to recommended fungicide programs in Alabama, 2017. PDMR. 12:CF034.

Hagan, A. K., Campbell, H. L., Bowen, K. L., and Wells, L. 2018a. Yield and disease response of recommended peanut cultivars to fungicide inputs in southeast Alabama, 2017. PDMR. 12:CF032.

Hagan, A. K., Campbell, H. L., Bowen, K. L., and Wells, L. 2018b. Yield response along with leaf spot and stem rot control with recommended fungicide programs on peanut, 2017. PDMR. 12:CF033.

Jaks, A. J., and Grichar, W. J. 2009a. Control of peanut disease with fungicides, 2007. PDMR. 3:FC035.

Jaks, A. J., and Grichar, W. J. 2009b. Using fungicides and spray programs to control peanut diseases, 2007. PDMR. 3:FC036.

Jaks, A. J., and Grichar, W. J. 2011. Control of peanut diseases with fungicides, Lavaca Co., Tx 2010. PDMR. 5:FC124.

Jaks, A. J., Grichar, W. J., and Besler, B. A. 2001a. Comparison of AU-Pnut advisory and calendar spray schedules for control of peanut diseases, 1999. F N Tests 56:FC37.

Jaks, A. J., Grichar, W. J., and Besler, B. A. 2001b. Control of peanut diseases with reduced rate fungicides and adjuvants, 1999. F N Tests 56:FC36.

Jaks, A. J., Grichar, W. J., and Besler, B. A. 2001c. Control of peanut foliar and soilborne diseases by advisory sprays of reduced rate fungicides, 1999. F N Tests 56:FC38.

Johnson George, K., Tiwari, S. P., and Reddy, P. S. 1988. Genetic variability for peg strength and related characters in groundnut (Arachis hypogaea). Indian J. Agric. Sci. 57:141-143.

Jordan, D. L., Brandenburg, R. L., Brown, A. B., Bullen, S. G., Buol, G., Dean, L., Foote, B., Hare, A., Kaufman, A., Reberg-Horton, C., Roberson, G. T., Shew, B., Washburn, D., and Wilkerson, G. 2018a. 2018 Peanut information. NC State Extension, Raleigh, NC

Jordan, D. L., Hare, A. T., Roberson, G. T., Shew, B. B., Brandenburg, R. L., Anco, D., Balota, M., Mehl, H., and Taylor, S. 2018b. Summary of variables associated with application of plant protection products in peanut. Crop Forage Turfgrass Manage. 4:180034

Jordan, D. L., Shew, B. B., and Johnson, P. D. 2016. Response of the peanut (Arachis hypogaea L.) cultivar Gregory to interactions of digging date and disease management. Adv. Agric. 2016:1-9.

Kemerait, R., Culbreath, A., Prostko, E., Brenneman, T., Tubbs, S., Srinivasan, R., Abney, M., Monfort, S., Rabinowitz, A., Tillman, B., Dufault, N., Rowland, D. Mulvaney, M., Small, I., Hagan, A., Sarver, J., Anco, D., and Smith, N. 2018. Peanut Rx: Minimizing Diseases of Peanut in the Southeastern United States. The 2018 Version of the Peanut Disease Risk Index. University of Georgia Extension, Athens, GA

Knauft, D. A., Gorbet, D. W., and Norden, A. J. 1988. Yield and market quality of seven peanut genotypes as affected by leafspot disease and harvest date. Peanut Sci. 15:9-13.

Kokalis-Burelle, N., Porter, D. M., Rodríguez-Kábana, R., Smith, D. H., and Subrahmanyam, P. 1997. Compendium of Peanut Diseases. 2nd ed. APS Press, St. Paul, MN.

Lin, L. I.-K. 1989. A concordance correlation coefficient to evaluate reproducibility. Biometrics 45:255-268.

Littell, R. C., Milliken, G. A., Stroup, W. W., Wolfinger, R. D., and Schabenberger, O. 2006. SAS System for Mixed Models. 2nd ed. SAS Institute Inc., Cary, NC.

Madden, L. V., Hughes, G., and van den Bosch, F. 2007. The Study of Plant Disease Epidemics. American Phytopathological Society, St. Paul, MN.

Madden, L. V., and Paul, P. A. 2011. Meta-analysis for evidence synthesis in plant pathology: An overview. Phytopathology 101:16-30.

Madden, L. V., Piepho, H. P., and Paul, P. A. 2016. Statistical models and methods for network meta-analysis. Phytopathology 106:792-806.

Mehl, H. L. 2015. Evaluation of registered and experimental foliar fungicides for control of peanut diseases, 2014. PDMR. 9:FC051.

Mehl, H. L., and Phipps, P. M. 2014a. Evaluation of foliar fungicides and a biological agent for control of peanut diseases, 2013. PDMR. 8: FC151.

Mehl, H. L., and Phipps, P. M. 2014b. In-furrow, emergence and foliar applications of fungicides for peanut disease control, 2013. PDMR. 8:FC168.

Nutter, F. W., Jr., and Littrell, R. H. 1996. Relationships between defoliation, canopy reflectance and pod yield in the peanut-late leafspot pathosystem. Crop Prot. 15:135-142.

Nutter, F. W., Jr., and Shokes, F. M. 1995. Management of foliar diseases caused by fungi. Pages 65-73 in: Peanut Health Management. H. A. Melouk and F. M Shokes, eds. APS Press, St. Paul, MN.

O’Brien, G. K., Barocco, R., Douglas, M. H., Wright, D. L., and Small, I. M. 2018. Evaluation of fungicides for the control of peanut diseases in Quincy, FL, 2017. Plant Dis. Manage. Rep. 12:CF087. 
O’Brien, G. K., George, S., Douglas, M. H., Marois, J. J., and Wright, D. L. 2015a. Evaluation of fungicides for the control of peanut diseases at the NFREC, Quincy, FL, June, 2014. PDMR. 9:FC036.

O'Brien, G. K., George, S., Douglas, M. H., Marois, J. J., and Wright, D. L. 2015 b. Evaluation of fungicides for the control of peanut diseases at the NFREC, Quincy, FL, May, 2014. PDMR. 9:FC072.

O’Brien, G. K., George, S., Douglas, M. H., Marois, J. J., and Wright, D. L. 2016. Evaluation of fungicides for the control of peanut diseases at the NFREC, Quincy, FL, 2015. PDMR. 10:FC020.

O'Brien, G. K., George, S., Douglas, M. H., Small, I. M., and Wright, D. L. 2017. Evaluation of fungicides for the control of peanut diseases in Quincy, FL, 2016. PDMR. 11:FC057.

Opoku, J., Byrd-Masters, L., and Mehl, H. L. 2016. Evaluation of in-furrow, emergence, and foliar fungicide sprays for control of foliar and soilborne diseases of peanut, 2015. PDMR. 10:FC135.

Pattee, H. E., Wynne, J. C., Young, J. H., and Cox, F. R. 1977. The seed-hull weight ratio as an index of peanut maturity. Peanut Sci. 4:47-50.

Phipps, P., and Hu, J. 2010. Effect of Proline, USF2019A, Provost and Vapam on Cylindrocladium black rot and yield of peanut, 2009. PDMR. 4:FC030.

Phipps, P. M., and Partridge, D. E. 2007. Evaluation of foliar fungicide programs for control of foliar and soilborne diseases on peanut, 2006. PDMR. 1:FC098.

Phipps, P. M., and Telenko, D. E. P. 2011. Effects of foliar fungicides on control of early leaf spot of peanut, 2010. PDMR. 5:FC017.

Phipps, P. M., and Telenko, D. E. P. 2012. Effects of in-furrow and early post emergence fungicide applications on leaf and soilborne diseases of peanut, 2011. PDMR. 6:FC009.

Ratkowsky, D. A. 1990. Handbook of Nonlinear Regression Models. Marcel Dekker, New York, NY.

Schabenberger, O., and Pierce, F. J. 2002. Contemporary Statistical Models for the Plant and Soil Sciences. CRC Press, Boca Raton, FL.

Shah, D. A., and Dillard, H. R. 2006. Yield loss in sweet corn caused by Puccinia sorghi: A meta-analysis. Plant Dis. 90:1413-1418.

Shew, B. B. 2018a. Labeled fungicides for peanut disease management in North Carolina, 2017. PDMR. 12:CF012.

Shew, B. B. 2018b. Peanut disease management in North Carolina with Elatus and Miravis, 2017. PDMR. 12:CF011.

Simmonds, M. C., Higgins, J. P. T., Stewart, L. A., Tierney, J. F., Clarke, M. J., and Thompson, S. G. 2005. Meta-analysis of individual patient data from randomized trials: A review of methods used in practice. Clin. Trials 2: 209-217.

Singh, M. P., Erickson, J. E., Boote, K. J., Tillman, B. L., Jones, J. W., and van Bruggen, A. H. C. 2011. Late leaf spot effects on growth, photosynthesis, and yield in peanut cultivars of differing resistance. Agron. J. 103:85-91.

Sorensen, R. B., Nuti, R. C., Holbrook, C. C., and Chen, C. Y. 2017. Peanut peg strength and associated pod yield and loss by cultivar. Peanut Sci. 44:77-82.

Stroup, W. 2013. Generalized Linear Mixed Models: Modern Concepts, Methods and Applications. CRC Press, Boca Raton, FL.

Telenko, D. E. P., and Phipps, P. M. 2012. In-furrow, emergence and foliar application of new fungicides for peanut disease control, 2011. PDMR. 6: FC012.

Thomas, R. J., Pettit, R. E., Taber, R. A., and Jones, B. L. 1983. Peanut peg strength: Force required for pod detachment in relation to peg structure. Peanut Sci. 10:97-101.

Thompson, S. G., and Higgins, J. P. T. 2002. How should meta-regression analyses be undertaken and interpreted? Stat. Med. 21:1559-1573.

Troeger, J. M., Williams, E. J., and Butler, J. L. 1976. Factors affecting peanut peg attachment force. Peanut Sci. 3:37-40.

USDA FSA. 2018. Peanut premiums and discounts for 2018 crop year. USDA FSA. https://www.fsa.usda.gov/Assets/USDA-FSA-Public/usdafiles/Price-Support/ pdf/2018/2018_peanuts.pdf.

USDA NASS. 2019. USDA NASS. https://www.nass.usda.gov/.

van Houwelingen, H. C., Arends, L. R., and Stijnen, T. 2002. Advanced methods in meta-analysis: Multivariate approach and meta-regression. Stat. Med. 21: 589-624.

Waggoner, P. E., and Berger, R. D. 1987. Defoliation, disease, and growth Phytopathology 77:393-398.

Wei, X., Byrd-Masters, L., and Mehl, H. L. 2018. Comparison of foliar fungicide programs for leaf spot and soilborne disease control in peanut in Virginia, 2017. PDMR. 12:CF041

Whitty, E. B., Sprenkel, R., Kucharek, T., Diskson, D., and Cockrell, P. 2000. Crop profile for peanuts in Florida. National Integrated Pest Management Database. https://ipmdata.ipmcenters.org/source_report.cfm? sectionid $=40 \&$ sourceid $=1365$

York, A. C., Jordan, D. L., and Wilcut, J. W. 1994. Peanut control in rotational crops. Peanut Sci. 21:40-43. 